\title{
Kondisi dan Pengelolaan Kawasan Hulu DAS Belawan Hubungannya dengan Tingkat Bahaya Erosi pada Lahan Budidaya di Kabupaten Deli Serdang
}

\author{
Anggy Palleriani Harahap ${ }^{1 *}$, Abdul Rauf ${ }^{2}$, Miswar Budi Mulya ${ }^{3}$ \\ 1,3Jurusan Pengelolaan Sumberdaya Alam \& Lingkungan, Sekolah Pascasarjana, Universitas Sumatera Utara, Medan \\ ${ }^{2}$ Jurusan Pertanian, Fakultas Pertanian, Universitas Sumatera Utara, Medan \\ *Koresponden email: anggyphrp@ gmail.com
}

Diterima: 21 Mei 2021

Disetujui : 1 Juni 2021

\begin{abstract}
The Belawan watershed is located at Deli Serdang Regency and Medan City, with mountainous terrain (70.58\%), hills (35.15\%), and slopes (20.28\%). This study aims to identify the risk of erosion of cropland, especially coffee, corn, and chocolate, to identify more appropriate erosion control measures to achieve regional protection objectives. The research was conducted in the upstream Belawan watershed in the Sibolangit, Bandar Baru, and Kutalimbaru regions from September 2020 to December 2020. The magnitude of the erosion hazard value is analysed using the USLE approach . The USLE method on the amount of erosion is determined by 5 (five) factors, these factors are the rainfall erosion factor (R); soil erodibility factor $(\mathrm{K})$; vegetation factor $(\mathrm{C})$; conservation factor $(\mathrm{P})$ and topography factor (LS). The erosion rate valuefor land use types varies from 95.27 tons/Ha.yr to 232.43 tons/Ha.yr. The amount of erosion that can be tolerated in land use for coffee, corn, and cacao ranges from 19.94 tons/Ha.yr to 39.79 tons/Ha.yr. The risk level for erosion in coffee areas 4.83 and 10.86 with high criteria and very high criteria; in areas of corn event 6.29 and 8.38 with high criteria and in brown areas 5.24 and 3.88 with high criteria and medium criteria.
\end{abstract}

Keywords: Belawan watershed, land use type, erosion hazard level, USLE, erosion

\begin{abstract}
Abstrak
DAS Belawan berlokasi di Kabupaten Deli Serdang dan Kota Medan, dengan medan pegunungan $(70,58 \%)$, perbukitan $(35,15 \%)$, dan lereng $(20,28 \%)$. Penelitian ini bertujuan untuk mengetahui secara berkelanjutan risiko erosi pada lahan budidaya, terutama kopi, jagung dan cokelat, sehingga dapat menentukan tindakan pengendalian erosi yang lebih sesuai untuk mencapai tujuan perlindungan kawasan. Penelitian dilakukan pada DAS Belawan bagian hulu di wilayah Sibolangit, Bandar Baru dan Kutalimbaru dari September 2020 hingga Desember 2020. Besarnya nilai bahaya erosi dianalisis menggunakan metode USLE. Metode USLE pada besarnya erosi ditentukan ditentukan oleh 5 (lima) faktor, faktor-faktor tersebut yaitu faktor erosivitas hujan (R); faktor erodibilitas tanah (K); faktor vegetasi (C) faktor konservasi (P) dan faktor topografi (LS). Nilai laju erosi pada ketiga jenis penggunaan lahan antara 95,27 ton/Ha.thn sampai 232,43 ton/Ha.thn. Pada penggunaan lahan kopi, jagung dan cokelat didapatkan nilai laju erosi yang ditoleransi antara antara 19,94 ton/Ha.thn sampai 39,79 ton/Ha.thn. Tingkat bahaya erosi pada area kopi 4,83 dan 10,86 dengan kriteria tinggi dan kriteria sangat tinggi; pada area jagung 6,29 dan 8,38 dengan kriteria tinggi dan pada area cokelat 5,24 dan 3,88 dengan kriteria tinggi dan kriteria sedang.

Kata Kunci: DAS Belawan, jenis penggunaan tanah, tingkat bahaya erosi, USLE, erosi
\end{abstract}

\section{Pendahuluan}

Erosi tanah atau soil erosion yang terjadi di permukaan dataran bumi merupakan kejadian pengikisan lapisan tanah atau hilangnya lapisan tanah [1]. Faktor-faktor alam yang berpengaruh dalam erosi adalah erodibilitas tanah, erosivitas hujan dan topografi, tetapi manusia juga berperan dalam terjadinya erosi di muka bumi ini [2]. Maka dari itu, pengunaan lahan yang tidak mengikuti kaidah-kaidah yang telah menjadi acuan (kaidah konservasi tanah dan air) akan menjadi salah satu penyebab erosi yang diakibatkan oleh pengaruh manusia [3]. Tidak diabaikannya keberlanjutan dari sumber daya lahan secara tidak langsung dapat memaksimalkan produktivitas lahan adalah fungsi dari manajemen lahan [4].

Daerah aliran Sungai Belawan merupakan salah satu DAS di Indonesia yang telah mengalami degradasi dalam sepuluh tahun terakhir ini, namun belum ada penanganan dan perhatian secara serius baik dari pemerintah setempat maupun masyarakat. Kawasan hulu DAS yang seharusnya merupakan kawasan hutan lindung mengalami alih fungsi menjadi kawasan perkebunan rakyat dan permukiman penduduk. DAS 
Belawan memiliki daerah yang sangat strategis sehingga menjadi penopang bagi ekonomi masyarakat dan memiliki fungsi ekologis bagi lingkungan setempat.

DAS Belawan terletak pada 2 (dua) daerah kabupaten maupun kota ialah Kabupaten Deli Serdang yang mempunyai luas 38.029,30 Ha ataupun sebesar 92,23\% dan Kota Medan mempunyai luas 2.760,69 Ha ataupun sebesar 6,77\%. Konsep suatu DAS merupakan konsep dari pembangunan suatu wilayah yang berdasarkan batas alamiah, yang mampu memadukan spesifik, sosial ekonomi, budaya, dan kelembagaan [5]. Peningkatan pemanfataan dan eksploitasi sumberdaya alam di daerah Indonesia dapat menyebabkan menurunnya kondisi dan mengakibatkan degradasi DAS. DAS yang sudah mengalami degradasi yang dapat dikategorikan sebagai DAS dalam kondisi agak kritis yang perlu untuk dipulihkan.

\section{Metode Penelitian}

\section{Lokasi Penelitian}

Lokasi penelitian ini berada di daerah aliran sungai Belawan wilayah Sumatera Utara yang memiliki luas sebesar 8.694,82 Ha yang terdapat di bagian hulu DAS Belawan. Secara administrasi hulu sungai Belawan terletak pada Kabupaten Deli Serdang yaitu Kecamatan Kutalimbaru dan Kecamatan Sibolangit yang bermuara pada daerah hilir di Kecamatan Hamparan Perak kemudian mengalir hingga ke Selat Malaka (Pantai Timur Sumatera Utara) [6]. Lokasi yang akan dilakukan penelitian berada di daerah hulu DAS Belawan di Kecamatan Sibolangit dapat dilihat pada Gambar 1.

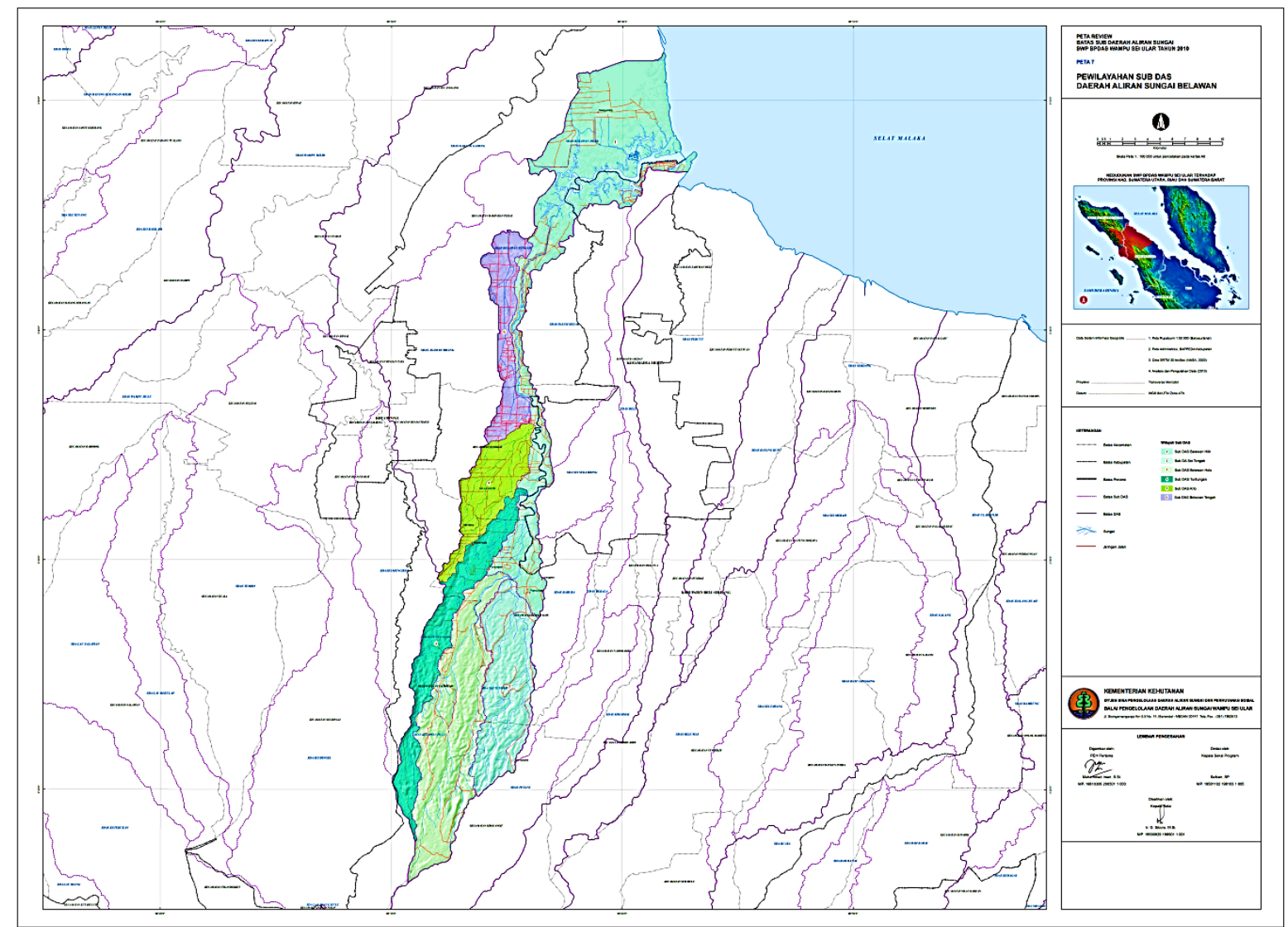

Gambar. 1. Lokasi penelitian

Sumber: Pewilayahan Sub DAS Aliran Sungai Belawan, Kementerian Kehutanan, 2020

\section{Alat dan Bahan}

Perlengkapan yang dipakai pada riset ini merupakan bor tanah, ring sample untuk tanah, GPS, kantong plastik, kertas, kawat, pisau, patok kayu, paku, karet, martil serta perlengkapan pertukangan yang lain, perlengkapan tulis, aplikasi SPSS 22 serta kamera. Sebaliknya bahan yang dibutuhkan dalam riset ini ialah tanah/ sedimen, air larian, peta administrasi, informasi sekunder curah hujan sepanjang 9 tahun terakhir.

\section{Analisis Data}

Analisis nilai erosi dihitung menggunakan rumus Smith dan Wischmeier (1978) dapat disebut juga dengan rumus USLE atau Universal Soil Loss Equation [7].

$A \quad=R \times K \times L S \times C \times P$ 
Keterangan:

$\mathrm{A}=$ Jumlah tanah yang hilang maksimum $(\mathrm{Ton} / \mathrm{Ha} / \mathrm{thn})$

$\mathrm{R} \quad=$ Faktor erosivitas hujan

$\mathrm{K}=$ Faktor erodibilitas tanah

LS $=$ Faktor indeks panjang dan kemiringan lereng

$\mathrm{C}=$ Faktor indeks pengelolaan tanaman

$\mathrm{P} \quad=$ Faktor indes konservasi tanah

\section{Laju Erosi yang Ditoleransikan $(T)$}

Laju erosi yang ditoleransikan adalah batasan maksimal dalam bahaya erosi yang masih diperkenanakan [8]. Laju erosi yang ditoleransikan (T) dihitung dengan menggunakan rumus Hammer [9].

$\mathrm{T}=\frac{d e . f d}{w} x B D$

dimana:

$\mathrm{T} \quad$ : laju erosi yang ditoleransikan (ton. Ha /thn)

de : faktor kedalaman tanah

df : kedalaman efektif tanah $(\mathrm{cm})$

$\mathrm{W} \quad$ : resource life (400 tahun)

BD : Bulk Density (kerapatan massa) $\left(\mathrm{gr} / \mathrm{cm}^{3}\right)$

\section{Tingkat Bahaya Erosi (TBE)}

Tingkat bahaya erosi ditentukan dengan dibandingkannya nilai erosi potensial dengan nilai erosi yang dapat ditoleransi. Semakin sedikit tanah yang dibolehkan atau ditoleransi semakin dangkal solum tanah dan tingkat bahaya erosi (TBE) menjadi cukup besar meskipun tidak terlalu besar tanah yang hilang [10].

$\mathrm{TBE}=\frac{A}{T}$

dimana :

TBE : tingkat bahaya erosi

A : erosi potensial (ton/Ha.thn)

$\mathrm{T} \quad$ : laju erosi yang ditoleransi (ton/Ha.thn)

\section{Hasil dan Pembahasan}

Faktor Erosivitas Hujan (R)

Nilai erosivitas hujan (R) yang terjadi pada DAS Belawan bagian hulu selama 9 tahun terakhir (2009 - 2018) diperoleh dari Statiun Hujan Pos Biru - Biru Deli Serdang Badan Meteorologi, Kimatologi, dan Geofisika Wilayah I Medan. Pada Tabel 1 didapatkan curah hujan bulanan rata-rata selama sembilan tahun adalah $241,4 \mathrm{~cm}$ dan pada November yang memiliki nilai $35,60 \mathrm{~cm}$ adalah curah hujan bulanan tertinggi yang kemudian diikuti oleh Desember sebesar 30,01 cm.

Tabel 1. Nilai erosivitas hujan selama 9 tahun terakhir (2009-2018)

\begin{tabular}{ccccc}
\hline Bulan & $\begin{array}{c}\text { CH bulanan rata- } \\
\text { rata }(\mathrm{cm})\end{array}$ & HH bulanan (days) & $\begin{array}{c}\text { CH max selama } 24 \\
\text { jam/bln }(\mathrm{cm})\end{array}$ & $\mathrm{R}(\mathrm{cm} / \mathrm{thn})$ \\
\hline Januari & 24.83 & 15 & 12.2 & 108.628 \\
Februari & 19.98 & 13 & 6.6 & 64.584 \\
Maret & 22.88 & 15 & 10.7 & 90.039 \\
April & 21.15 & 14 & 9.6 & 82.080 \\
Mei & 9.07 & 6 & 12.7 & 51.139 \\
Juni & 9.17 & 7 & 8 & 36.772 \\
Juli & 9.81 & 7 & 6.2 & 36.112 \\
Agustus & 13.59 & 9 & 5.6 & 43.243 \\
September & 17.13 & 10 & 10.5 & 77.462 \\
Oktober & 28.18 & 14 & 11.3 & 125.748 \\
November & 35.60 & 17 & 14.1 & 169.178 \\
\hline
\end{tabular}




\begin{tabular}{ccccc}
\hline Desember & 30.01 & 17 & 9.1 & 108.481 \\
Total & 241.4 & 144 & 116.6 & 993.466 \\
\hline
\end{tabular}

Sumber: Pengolahan data, 2021

Pada Tabel 1 diperoleh nilai erosivitas hujan (R) tertinggi pada bulan November, Oktober, dan Januari. Nilai erosivitas hujan (R) yang terjadi di bulan Juni, Juli, dan Agustus dengan nilai erosivitas hujan terendah.

\section{Pengelolaan Kawasan Hulu DAS Belawan Terhadap Faktor Erosivitas Hujan (R)}

Faktor yang sangat berpengaruh pada erosi ialah curah hujan atau faktor iklim. Erosivitas hujan (R) termasuk dalam faktor yang berpengaruh terhadap besarnya nilai erosi tanah. Curah hujan yang turun adalah ciri karakteristik pengaruh jenis erosi yang terjadi pada suatu tempat [10]. Tingginya intensitas hujan maka semakin tinggi pula tenaga tumbukan dan percikannya maka semakin banyak pula partikel tanah yang terlepas dan kemudian telempar bersama percikan air [11]. Besarnya nilai erosivitas hujan pada kawasan hulu DAS Belawan tertinggi terjadi pada bulan November, Oktober, dan Januari. Pada bulan-bulan basah ini memiliki nilai distribusi hujan yang relatif tinggi, sehingga diharapkan tidak melalukan pembersihan tanaman penutup, land clearing dan pembersihan gulma. Tindakan yang dilakukan agar mengurangi aliran permukaan mencegahnya percikan air hujan yang jatuh ke tanah secara langsung sehingga tetap menjaga kemantapan struktur tanah. Adapun hal - hal yang dapat dilakukan pada bulan yang nilai distribusi hujannya tinggi, yaitu menggunakan penutup lahan (daun kering dan mulsa) dan untuk memperkecil terjadinya run off dapat dilakukan penambahan bahan organik fungsinya untuk mempertahankan agregat tanah.

\section{Faktor Erodibilitas Tanak (K)}

Faktor erodibilitas tanah $(\mathrm{K})$ diperoleh melalui uji laboratorium dan pengamatan sifat dari fisikakimia. Nilai erodibilitas tanah (K) dapat dilihat pada Tabel 2.

Tabel 2. Nilai K pada lahan kopi, jagung dan cokelat

\begin{tabular}{lcccccc}
\hline \multirow{2}{*}{ Penggunaan Lahan } & Sampel & $\begin{array}{c}\text { Tekstur } \\
\text { Tanah } \\
\text { (M) }\end{array}$ & $\begin{array}{c}\text { Kode Bahan } \\
\text { Organik } \\
\text { (a) }\end{array}$ & $\begin{array}{c}\text { Kode } \\
\text { Stuktur } \\
\text { (b) }\end{array}$ & $\begin{array}{c}\text { Kode Permeabilitas } \\
\text { (c) }\end{array}$ & $\begin{array}{c}\text { Erodibilitas Tanah } \\
\text { (K) }\end{array}$ \\
\hline \multirow{2}{*}{ Kopi } & KP1 & 2200,75 & 1,482 & 3 & 3 & 0,216 \\
& KP 2 & 3107,60 & 1,068 & 3 & 3 & 0,316 \\
\multirow{2}{*}{ Cokelang } & JG 1 & 2200,75 & 0,81 & 3 & 3 & 0,276 \\
& JG 2 & 3107,60 & 1,32 & 3 & 3 & 0,418 \\
& CK 1 & 2871,56 & 0,99 & 3 & 3 & 0,290 \\
& CK 2 & 2347,65 & 0,18 & 3 & 3 & 0,240 \\
\hline
\end{tabular}

Sumber: Pengolahan Data, 2021

Dari Tabel 2 tingkat kelas kepekaan tanah / nilai erodibilitas agak tinggi pada lahan budidaya jagung (JG2) sebesar 0,418 dan kemudian kelas kepekaan tanah / nilai erodibilitas agak rendah terdapat pada lahan budidaya kopi (KP2) sebesar 0,316 kemudian pada lahan budidaya cokelat (CK1) sebesar 0,290; pada lahan budidaya jagung (JG1) sebesar 0,276; pada lahan budidaya cokelat (CK2) sebesar 0,240 dan pada lahan budidaya kopi (KP1) sebesar 0,216. Dampak dari laju permeabilitas tanah dengan kepekaan tanah atau erodibilitas tanah terhadap erosi tidaklah sama atau berbanding terbalik, sehingga dapat disimpulkan semakin tinggi laju permeabilitas, maka erodibilitas tanah terhadap erosi semakin rendah [9].

\section{Pengelolaan Kawasan Hulu DAS Belawan Terhadap Faktor Erodibilitas Tanah (K)}

Nilai erodibilitas tanah pada hulu DAS Belawan terhadap erosi kemungkinan erosi yang terjadi pada jenis tanah ini adalah rendah, maka dari itu diharapkan agar tetap mempertahankan unsur organik dalam tanah. Fungsi dari unsur organik adalah untuk memperbaiki struktur tanah dan meningkatkan permeabilitas dan menjaga kesuburan tanah. Dengan demikian dapat menghambat dan memperlama kecepatan air limpasan dan akan menurunkan kemungkinan terjadinya erosi. Struktur tanah granuler yang mempengaruhi besar atau kecilnya kapasitas masuknya air kedalam tanah (infiltrasi) jika kapasitas air dalam tanah tinggi maka kapasitas infiltrasi tanah akan naik atau meningkat. Maka dari itu laju air yang masuk kedalam tanah memiliki fungsi untuk pertumbuhan tanaman dengan meningkatnya jumlah air yang ada di dalam tanah dan dapat juga menurunkan tingkat bahaya dari erosi dan banjir yang disebabkan dari limpasan permukaan (run off). Permeabilitas yang tinggi juga memiliki kemampuan untuk menaikan laju air dalam tanah (infiltrasi). 


\section{Faktor Topografi (LS)}

Faktor kemiringan lereng (S) dan faktor panjang lereng (LS) adalah faktor-faktor yang mempengaruhi faktor topografi. Nilai faktor topografi dapat dilihat pada Tabel 3.

Tabel 3. nilai topografi (ls)

\begin{tabular}{ccccc}
\hline Sampel & $S\left(^{\circ}\right)$ & $S(\%)$ & $L(\mathrm{~mm})$ & $L S$ \\
\hline KP 1 & 14,7 & 32,67 & 22 & 6,42 \\
KP 2 & 15,9 & 35,33 & 22 & 6,71 \\
JG 1 & 14,9 & 31,78 & 22 & 6,32 \\
JG 2 & 15,4 & 33,99 & 22 & 6,43 \\
CK 1 & 14,5 & 32,22 & 22 & 6,35 \\
CK 2 & 15,7 & 34,89 & 22 & 6,66 \\
\hline
\end{tabular}

Sumber: Pengolahan data, 2021

Dari Tabel 3 yang disajikan terdapat kemiringan lerang pada penggunan lahan budidaya rata-rata diatas $31 \%$. Nilai kemiringan yang paling ekstrem atau curam sekitar 35,33\% pada lahan kopi (KP2) dan kemiringan paling rendah sebesar 31,78\% pada lahan jagung (JG1). Keadaan topografi hulu DAS Belawan relatif curam, sehingga memungkinkan potensi erosi yang relatif besar pula. Dengan topografi yang dimiliki DAS Belawan kondisinya pada sepanjang pinggiran sungai hampir merata relatif curam. Dengan kondisi tersebut berdampak pada besarnya erosi yang akan terjadi.

\section{Pengelolaan Kawasan Hulu DAS Belawan Terhadap Faktor Topografi (LS)}

Pada erosi yang terjadi faktor lereng sangat berpengaruh. Ref. [12][13] menyatakan bahwa semakin panjangnya lereng, semakin besar jumlah lebihnya air di atas maka semakin besar kenaikannya dan akan meningkatkan kecepatan turunnya. Kondisi lereng pada hulu DAS Belawan memiliki kemiringan yang merata tetapi untuk kondisi topografi pada hulu DAS Belawas di sepanjang pingiran sungai adalah relatif curam. Hal yang akan terjadi jika keadaan topografi pada daerah hulu DAS Belawan relatif curam berdampak pada besarnya erosi yang akan terjadi. Dalam hal ini dapat dilakukannya konservasi tanah secara mekanis, konservasi tanah secara mekanis memiliki fungsi yaitu mengalirkan air dari permukaan, meningkatnya tekanan infiltrasi dan menyediakan air untuk tanaman. Metode mekanik termasuk dalam usaha konservasi tanah, adapun salah satu contohnya yaitu pengolahan tanah, pengolahan tanah menurut garis kontur dan pembuatan teras.

\section{Faktor Vegetasi $(C)$ dan Faktor Konservasi $(P)$}

Vegetasi yang diteliti pada DAS Belawan berupa kopi, jagung dan cokelat pada setiap vegetasi memiliki 2 (dua) sampel dengan nilai yang terdapat pada Tabel 4. Penanaman dengan kontur merupakan perlakuan teknik konservasi yang dipakai dalam sampel yang diambil pada penelitian ini.

Tabel 4. Nilai faktor $\mathrm{CP}$ (faktor penutup vegetasi dan tindakan konservasi)

\begin{tabular}{cccc}
\hline Tanaman Budidaya & $C$ & $P$ & $C P$ \\
\hline Kopi & 0,6 & 0,20 & 0,12 \\
Jagung & 0,64 & 0,20 & 0,128 \\
Cokelat & 0,3 & 0,20 & 0,06 \\
\hline
\end{tabular}

Sumber: Pengolahan data, 2021

\section{Pengelolaan Kawasan Hulu DAS Belawan Terhadap Faktor Vegetasi (C) dan Faktor Konservasi (P)}

Tidak mengikuti kaidah konservasi tanah dan air dalam praktik budidaya pertanian dapat menyebabkan dampak yang serius. Dampak yang disebabkan adalah terjadinya degradasi lahan. Pada usaha pertanian yang potensial terdapat dua faktor yang menunjukkan keseluruhan pengaruh dari vegetasi, seresah, keadaan permukaan tanah juga pengelolaan lahan terhadap besarnya tanah yang hilang atau erosi dan faktor manusia yang menjalankan pertanian. Hutan lindung yang sudah berubah fungsinya kini menjadai kawasan untuk usaha tani dan menjadi kawasan perkebunan rakyat maupun swasta, hal ini akan menyebabkan perubahan yang sangat signifikan terhadap kondisi fisik yang dimiliki oleh tanah.

Salah satu berubahnya kondisi fisik tanah dapat menyebabkan cepatnya laju aliran air yang ada di permukaan tanah yang akan menimbulkan erosi. Dengan mengikuti konservasi tanah dan air merupakan cara pengelolaan tanaman penutup untuk menghindari erosi yang terjadi. Fungsi dari pengelolaan tanaman penutup tanah ialah mengurangi laju masuknya air kedalam tanah sehingga dapat menimalisir erosi yang akan terjadi [14][15]. Tanaman penutup dapat dipilih dengan melihat manfaat tanaman tersebut dalam untuk lingkungan dan penduduk yang memiliki pekerjaan petani mendapatkan penghasilan lebih dari tanaman penutup tersebut. Tanaman yang memiliki kriteria seperti itu salah satu contohnya adalah bambu. 
Stuktur akar yang dimiliki oleh bambu sangatlah kuat, akar tersebut dapat menahan laju erosi yang akan terjadi. Bagian tubuh bambu lainnya dapat dimanfaatkan dan memiliki nilai ekonomis untuk dijual.

\section{Analisis Faktor-Faktor yang Mempengaruhi Besarnya Erosi}

Statistik regresi berganda digunakan untuk menganalisis besarnya erosi. Analisis regresi ini digunakan pada ketiga lahan yaitu kopi, jagung dan cokelat yang memiliki nilai koefisien yang sama sehingga pengaruh pada nilai erosi yang didapat adalah nyata dan seimbang, semakin besar nilai koefisien dari faktor-faktor yang dianalisis maka besar pula dampak yang diakibatkan seperti besarnya nilai erosi yang akan terjadi pada hulu DAS Belawan.

Berdasarkan Tabel 5 ketiga faktor tersebut menunjukan bahwa sangat berpengaruh terhadap besarnya erosi [8]. Analisis sidik ragam yang dilakukan pada besarnya erosi yang memiliki nilai Frattio sebesar 203,335, sedangkan nilai $F$ tabel sebesar 19,1643. Maka dasar pengambilan keputusan adalah:

Ho: tidak ada pengaruh yang signifikan antara faktor K, LS dan C secara bersama - sama terhadap nilai erosi.

Ha: ada pengaruh yang signifikan antara faktor K, LS dan C secara bersama - sama terhadap nilai erosi

maka,

Frattio < F tabel maka Ho diterima

$203,335>19,164$

Tabel 5. Parameter persamaan regresi erosi

\begin{tabular}{cccccc}
\hline Independent variable & Regession coefficients & $F$ & $T$ & Sig & Adjusted $R^{2}$ \\
\hline Erodibilitas (K) & 111,082 & & 16,705 &, 004 & \\
Kemiringan Lereng (LS) & 6,974 & & 4,725 &, 042 & \multirow{2}{*}{0.993} \\
Tanaman Penutup (C) & 109,113 & 203,335 & 20,668 &, 002 & \\
Constant (a) & $-76,747$ & & $-7,451$ &, 018 & \\
\hline
\end{tabular}

Sumber: Pengolahan data, 2021

Diperoleh kesimpulan bahwa Ho yang dianalisis ditolak, artinya secara signifikan memiliki pengaruh antara antara faktor K, LS dan C secara bersamaan terhadap nilai erosi yang diperoleh.

Pengukuran Laju Erosi

Dari 6 (enam) titik penelitian pada bagian hulu DAS Belawan pada lahan kemiringan lereng antara $31,78 \%$ sampai 35,33\%, diperoleh hasil yang dapat dilihat pada Tabel 6, pada lahan kopi sebesar 96,43 ton/Ha.thn dan 232,43 ton/Ha.thn, pada lahan jangung ialah 221,81 ton/Ha.thn dan 341,78 ton/Ha.thn, pada cokelat didapat sebesar 109,75 ton/Ha.thn dan 95,27 ton/Ha.thn.

Tabel 6. Nilai erosi menggunakan metode USLE

\begin{tabular}{clc}
\hline No. & Penggunaan Lahan & Erosi Prediksi USLE (A) (ton/Ha.thn) \\
\hline 1. & KP 1 & 96,43 \\
2. & KP 2 & 232,43 \\
3. & JG 1 & 221,81 \\
4. & JG 2 & 341,78 \\
5. & CK 1 & 109,76 \\
6. & CK 2 & 95,27 \\
\hline
\end{tabular}

Sumber: Pengolahan data, 2021

\section{Laju Erosi yang Ditoleransikan (T)}

Pada Tabel 7 dibawah ini diperoleh hasil perhitungan laju erosi yang ditoleransikan. Ref. [9] menyatakan bahwa batas toleransi adalah batas untuk toleransi erosi ialah batas nilai maksimal pada besar erosi yang diperbolehkan. Batas erosi yang diperkenankan dipengaruhi oleh iklim, erodibilitas tanah dan batuan pembentuk tanah. 
Tabel 7. Nilai laju erosi yang ditoleransikan pada lahan kopi, jagung, dan cokelat

\begin{tabular}{clc}
\hline No. & Penggunaan Lahan & T (ton/Ha.thn) \\
\hline 1. & KP 1 & 19,94 \\
2. & KP 2 & 21,39 \\
3. & JG 1 & 35,25 \\
4. & JG 2 & 39,79 \\
5. & CK 1 & 20,91 \\
6. & CK 2 & 24,45 \\
\hline
\end{tabular}

Sumber: Pengolahan data, 2021

\section{Tingkat Bahaya Erosi}

Pada lahan kopi, jagung dan cokelat terdapat tingkat bahaya erosi dapat dilihat Tabel 8 di bawah ini. Tingkat bahaya erosi dihitung untuk dapat membandingkan nilai erosi (A) dengan nilai erosi yang ditoleransikan $(\mathrm{T})$. Tingkat bahaya erosi pada bagian hulu DAS Belawan di Tabel 8 didapat kesimpulan bahwa yang berpengaruh pada tingkat bahayaa erosi secara signifikan adalah tanaman penutup lahan (C). Jenis tanaman yang berpengaruh pada tingkat bahaya erosi yang akan terjadi adalah jenis tanaman kopi.

Tabel 8. Nilai tingkat bahaya erosi menggunakan metode USLE

\begin{tabular}{|c|c|c|c|c|c|}
\hline No. & Penggunaan Lahan & $\begin{array}{l}\text { Erosi }(\mathrm{A}) \\
\text { (ton.Ha/thn) }\end{array}$ & $\begin{array}{l}\text { Erosi yang ditoleransi (T) } \\
\text { (ton/Ha.thn) }\end{array}$ & $(\mathrm{TBE})$ & Keterangan \\
\hline 1. & KP 1 & 96,43 & 19,94 & 4,83 & Tinggi \\
\hline 2. & KP 2 & 232,43 & 21,39 & 10,86 & Sangat Tinggi \\
\hline 3. & JG 1 & 221,81 & 35,25 & 6,29 & Tinggi \\
\hline 4. & JG 2 & 341,78 & 39,79 & 8,58 & Tinggi \\
\hline 5. & CK 1 & 109,76 & 20,91 & 5,24 & Tinggi \\
\hline 6. & CK 2 & 95,27 & 24,54 & 3,88 & Sedang \\
\hline
\end{tabular}

Sumber: Pengolahan data, 2021

\section{Pengelolaan Kawasan Hulu DAS Belawan Terhadap Tingkat Bahaya Erosi (TBE)}

Erosi tanah bisa berbahaya jikalau erosi yang berlangsung lebih cepat daripada laju terbentuknya tanah. Erosi bila dibiarkan terus menerus akan menipiskan kedalaman tanah yang pada akhirnya akan merusak lapisan atas tanah (up land). Tingkat bahaya erosi yang diperoleh di kawasan hulu DAS Belawan memiliki kategori sedang, tinggi dan sangat tinggi. Maka dari itu untuk mengurangi tingkat bahaya erosi pada DAS Belawan untuk membantu air yang diserap masuk kedalam tanah sehingga mengurangi potensi terjadinya erosi diwajibkan untuk memiliki jenis pohon atau vegetasi yang dapat mengurangi potensi tersebut [15].

Pengendalian erosi dilakukan melalui tiga metode, yaitu metode pertama adalah metode vegetasi (biologi) yang menggunakan tumbuhan dan sisa-sisanya untuk mengurangi daya rusak hujan yang jatuh, jumlah dan daya rusak permukaan, penanaman tanaman penutup tanah, penggiliran tanaman dan penanaman tanaman dalam jalur. Metode kedua adalah metode teknis mekanis yaitu dengan cara pengawetan tanah untuk mengurangi jumlah tanah yang hilang pada lahan pertanian. Metode ketiga adalah metode kimiawi yaitu metode yang menggunakan bahan campuran kimia sintetis atau alami. Metode ini juga dapat disebut dengan soil conditioner yang memiliki tujuan untuk memperbaiki struktur tanah yang rusak.

\section{Aspek Sosial Ekonomi Masyarakat di Sekitar DAS Belawan}

Berdasarkan hal-hal yang ditemukan melalui penelitian ini terbukti bahwa berbagai kondisi yang menyangkut DAS Belawan pada akhirnya akan mempengaruhi kualitas sumberdaya lahan. Oleh karena itu, sebagai bagian dari ekosistem, masyarakat di sekitar DAS Belawan sangat berperan dalam memberikan kontribusi terhadap berbagai perubahan kondisi lingkungan.

Tabel 9. Penghasilan dan pekerjaan masyarakat kawasan hulu DAS Belawan

\begin{tabular}{ccccccc}
\hline \multirow{2}{*}{ Desa } & \multirow{2}{*}{ Jumlah Responden } & \multicolumn{3}{c}{ Penghasilan } & \multicolumn{3}{c}{ Pekerjaan } \\
\cline { 3 - 7 } & & $<1.000 .000$ & $<2.000 .000$ & $<3.000 .000$ & Petani & Wiraswasta \\
\hline Bandar Baru & 10 & 9 & 1 & 0 & 8 & 2 \\
Sibolangit & 10 & 4 & 5 & 1 & 10 & 0 \\
Kutalimbaru & 10 & 7 & 2 & 1 & 9 & 1 \\
\hline
\end{tabular}

Sumber: Wawancara, 2020 
Berdasarkan hasil wawancara dengan masyarakat, diperoleh informasi yang dapat dilihat pada Tabel 9 sebagian besar mata pencaharian masyarakat adalah sebagai petani $(69,12 \%)$, selain itu sebagai wiraswasta $(20,21 \%)$ sebagai pedagang dan peternak masing - masing sebanyak $10,67 \%$. Pada Tabel 10 lokasi hulu DAS Belawan ditemukan pula aktifitas masyarakat di tepian sungai yaitu aktifitas pertanian dan perkebunan. Masih lemahnya, pemahaman masyarakat terhadap kondisi sungai dan pemanfaatannya ternyata disebabkan oleh masih rendahnya tingkat sosialisasi dan pembinaan mengenai pengelolaan sungai.

Tabel 10. Komoditi dan topografi kawasan hulu DAS Belawan

\begin{tabular}{cccccccc}
\hline \multirow{2}{*}{ Desa } & Jumlah & \multicolumn{4}{c}{ Komoditi } & \multicolumn{2}{c}{ Topografi } \\
\cline { 3 - 8 } & Responden & Jagung & Coklat & Kopi & $\begin{array}{c}\text { Komoditi } \\
\text { Lain* }\end{array}$ & Datar & Miring \\
\hline Bandar Baru & 10 & 5 & 0 & 0 & 5 & 8 & 2 \\
Sibolangit & 10 & 5 & 0 & 0 & 5 & 8 & 2 \\
Kutalimbaru & 10 & 3 & 1 & 4 & 2 & 7 & 3 \\
\hline
\end{tabular}

*komoditi lain: cabai, bawang, kacang panjang, ubi, pinang dan jambu

Sumber: Wawancara, 2020

\section{Kesimpulan}

Berdasarkan hasil analisis dari penelitian ini, maka ditarik kesimpulan tingkat bahaya erosi pada lahan kopi 4,83 (kriteria tinggi) dan 10,86 (kriteria sangat tinggi), pada lahan jagung sebesar 6,29 (kriteria tinggi) dan 8,58 (kriteria tinggi) sedangkan pada lahan cokelat sebesar 5,24 (kriteria tinggi) dan 3,88 (kriteria sedang). Berdasarkan wawancara sosial ekonomi masyarakat diketahui penghasilan masyarakat setempat dibawah Rp.1.000.000-, dengan mata pencaharian ssebagai petani. Beberapa usulan dari masyarakat di sekitar sungai juga sempat terindentifikasi dalam penelitian ini perlu mendapat penilitian dari pemerintah kabupaten, provinsi maupun pemerintah pusat.

\section{Daftar Pustaka}

[1] T. Fendi, "Kajian di Desa Selopamioro Kecamatan Imogiri Kajian Tingkat Bahaya Erosi Selopamioro Kecamatan Imogiri Kabupaten Bantul Yogyakarta," Tesis, UPN Veteran. Yogyakarta, 2013.

[2] Dewi I.G.A.S.U M.T. Ni, K. "Prediksi Erosi dan Perencanaan Konservasi Tanah dan Air pada Daerah Aliran Sungai Saba," J. Argoteknologi Tropika, Vol. 1(1), 2012.

[3] A. Syofyan, "Kajian Tingkat Bahaya Erosi (TBE) pada Berbagai Tipe Penggunaan Lahan di Sub Daerah Aliran Sungai Lau Biang (Kawasan Hulu DAS Wampu)," Tesis, Sekolah Pascasarjana USU, Universitas Sumatera Utara, Medan, Sumatera Utara, Indonesia, 2010.

[4] Arwindrasti, B.K, "Kajian Karakteristik Hidrologi DAS Cisdane," Tesis Magister, Institut Pertanian Bogor, Bogor, 2017.

[5] R. Mira, "Kebijakan Pembangunan Berkelanjutan yang Berwawasan Lingkungan di Indonesia," Jurnal Kelola: Jurnal Ilmu Sosial, vol 1 no 1, 2018

[6] S. Mizanuddin dan Z. Asril,"Studi Potensi Daerah Genangan Banjir DAS Belawan Dengan Sistem Informasi Geografis (SIG)," Progress in Civil Engeneering, Journal, 1 (1), 2019.

[7] Asdak, C,"Hidrologi dan Pengelolaan Daerah Aliran Sungai," Gadjah Mada University Press, Yogyakarta, 2010.

[8] Harahap dan U. Kalsum, "Kajian Tingkat Bahaya Erosi (TBE) pada Lahan Perkebunan di Hulu DAS Batang Pane, Padang Lawas Utara," Universitas Sumatera Utara, Medan, Indonesia, 2016.

[9] Arsyad, S,"Konservasi Tanah dan Air," Edisi Kedua, IPB Press, Bogor, 2010.

[10] Karyati, "Parameter-Parameter Curah Hujan yang Mempengaruhi Penaksiran Indeks Erosivitas Hujan di Sri Aman," Serawak, Fakultas Kehutanan, Universitas Mulawarman, Kampus Gunung Kelua Samarinda, Indonesia, 2015.

[11] A. Sitanala,"Konservasi Tanah dan Air," IPB Press, Bogor, 2010.

[12] D. Rangkuti, "Analisa dan Pengendalian Erosi Permukaan pada Sub DAS Batang Angkola di Tapanuli Selatan," Tesis, Program Pascasarjana, Magister Pengembangan Sumberdaya Alam dan Lingkungan, USU, Medan, 2010.

[13] P. Pasaribu,"Kajian Tingkat Bahaya Erosi Pada Berbagai Tipe Penggunaan Lahan di Kecamatan Merdeka Kabupaten Karo,"Jurnal Serambi Engineering, Volume III, No. 1, 2018.

[14] Bukhari, I., Lubis, K. S., \& Lubis, A,"Pendugaan Erosi Aktual Berdasarkan Metode USLE Melalui Pendekatan Vegetasi, Kemiringan Lereng dan Eroddibilitas di Hulu Sub DAS Padang," Agroteknologi, 2014. 
[15] Suriadikusumah, A., Herdiansyah, G,'Dampak Beberapa Penggunaan Lahan Terhadap Erosi di Sub DAS Cisangkuy," Hal 9, 2011. 